This is an Accepted Manuscript of an article published by Taylor E Francis Group in

Third Text Vol. 22, Issue 1, January, 2008, 57-69.

Available online: http://www.tandfonline.com/doi/full/10.1080/09528820701855350

\title{
Plan and Conflict
}

\section{Networked Istanbul}

Peter Mörtenböck \& Helge Mooshammer

On 24 December 2006, the British newspaper The Observer featured a story about Noor, a seventeen-year-old Afghan, who like so many before had got stranded in the woods near Sangatte in France. Having paid US\$10,000 to a people trafficker, he set forth on his clandestine journey from a refugee camp outside the Pakistani frontier town of Peshawar, while his home country continued to be occupied by British and allied forces. Trying to reach his desired destination, the 'promised land' of the United Kingdom via Iran, Turkey, Greece, Italy and France, Noor spent five months living rough on the streets of Istanbul. ${ }^{1}$ This was more or less the same length of time the two curators of the 9th Istanbul Biennial in 2005, Charles Esche and Vasif Kortun, had envisaged for participating artists such as Dan Perjovschi, Phil Collins or Nedko Solakov to spend in Istanbul, so as to gain a deeper understanding of the city's urgencies when developing their artistic responses. One of the proposals for the Biennial, a project by the translocal art and architecture collective xurban, however, never made it to the actual exhibition space. Instead, it had to seek shelter inside the jacket of the exhibition catalogue.

What these stories have in common is their indication of an increasing entanglement of material and symbolic flows worldwide - a global circulation of capital, people and goods, without these flows necessarily being visible to each other. This accelerated politics of display and disguise is intrinsically linked to socio-political confrontations between hegemonic efforts to control these dynamics and the struggle for survival of the dispossessed and displaced. It gives rise to ever expanding distributed networks, whose channels are effect 
and means at the same time. They facilitate cross-border movements which react to interrelated logics and intersect at crucial sites of accumulation, but are not interdependent via central coordination. These networks have become the defining feature of twenty-first century social and spatial organisation. They have changed the ways we produce and experience the spaces we live in: cities, regions or countries are no longer stable territories but emerge as highly contested and fragile topologies performed by networks of interacting realities. Within this transformed global sphere the new mega-cities and the boundaries of economic zones have become urgent sites for experiencing the effects of mosaic universes, a term used by Maurizio Lazzarato to characterise the universe of global movements where things and beings do not converge on a totality but assert their mutual relatedness through 'inventing junctions and disjunctions that construct combinations which are always singular, contingent and not totalising'. ${ }^{2}$ One of the key criteria for the productivity and lifespan of such networked movements is their transformative potential, ie, the degree to which they are able to transform themselves into something else, rendering relationality an active and collaborative evasion of fixed identities. This potentiality makes them important devices in developing translocal agency and in producing counter-geographies in a climate of monopolised geopolitical change.

But how do such networks and their models of relationality cohere and how do they intersect with agencies that drive globalisation? That is to say: what kinds of encounters and exchanges do take place in Istanbul? Global economies, property developments, art markets, international biennials and newly implemented 'one stop shops' for foreign investors have all made their mark on the city, and it is in the light of this rapidly accumulated stratification of highly diverse translocal interests that Istanbul has become a prime site for the art world to articulate the increased tension between processes of unplanned urbanisation and systems of urban control.

We want to address this constellation by bringing together two different cultural urgencies with regard to urban transformations under way in Istanbul. The first is the troubled relation between space and conflict and, in particular, possible ways in which the rhetorics of 'contested spaces' can be shifted from determining a territorial situation marked by dichotomies of us/them, 
here/there or centre/periphery, to ones indicting discursive and political constructs in which the urban system features as a focus of political conflict. Our second concern relates to the production of what has been called 'shared horizons' or 'mutual orientations' generated through network agency without resorting to old models of institutional, historical or territorial belonging. The way we approach these combined urgencies in this text is by considering the crossroads of various sites of networked creativity which have emerged from the fields of geocultural art and architectural practices and the trajectories of global movements which are actualised at the marketplaces of global relations.

In network operation there is little difference between activity and outcome. To some extent, as Michael Hardt and Antonio Negri note in their discussion of multitudinous collaboration, the organisation becomes an end in itself. ${ }^{3}$ That is to say, the network organisation is both content and achievement. It entails the act as well as what is produced by the act. As networks are generically defined through the acts in which they congregate (the actions in which they are performed), they gather topological presence through an ongoing transfer of meanings and values into the realm of political action. This kind of network transformation does not contend for a new static category of space, but draws attention to performativity as the fundamental logic of social life today. It implies changes characteristic of agency in relation to networking as such, but also reverberates in new organisational and spatial patterns as well as in the production of network actors themselves.

When conceptualising such ontological concomitances, it seems vital to take into account a variety of different agencies, including those of scattered experiments pertaining to the realm of relational art and architecture practices. The support they lend in mobilising 'boundary-objects', which allow both uprooting and stabilisation of actors, brings into play the question of reciprocity, a reciprocity that is not fuelled by the ideologies of global dependencies and the politics of cultural capital but offers mutual support in transversal network organisation. This reciprocity is not an abstract concept one can adapt and apply to instrumental purposes, but a way of giving space to transformations which include the transformation of oneself. A model of hidden improprieties emerges from the trajectories of these 'grey' economies, an epistemic model which includes the production as well as the deferral, 
obfuscation and active withdrawal of knowledge; the destabilisation and virtualisation of the actual object in favour of its potential implications for something else; the perpetual movement of spontaneous emergence, dispersal and re-aggregation. This set of indeterminacies and improprieties allows us to think of possibilities for cultural encounters as a way of deliberately engaging one another outside the domains of transparency, clear calculation, disentanglement and illusory ideal speech situations.

\section{Contaminations}

The biennial proposal of the Istanbul and New York-based art collective xurban built upon the creation of such a third ground by transferring an existing social and economic network rife with 'improper' relations into the museum context. They modelled their contribution on the dominant politics towards the transnational exchange of highly desirable and undesirable things. Part of this work is a text about the project proposal hidden on the back of a specially designed fold-out jacket for the biennial catalogue, which aims to link three otherwise unconnected spaces in the neighbourhood of Karaköy: the space of brothels (Kerhane/Genelev) in the backstreets, the space of workshops and small facilities for the production and assembling of chandeliers, and the space of ablution (Abdesthane) in mosques in close vicinity to Karaköy. Xurban's project aimed to examine how these seemingly separate spaces of sex, money and religion are closely interlinked through a repertoire of minor acts and gestures recurring in day-to-day life. The flows of material and sexual production, the rituals of cleansing, the men lingering around house entrances, the acting out of control over territory - there are numerous spatial analogies of distinct modes of urban pursuit which point at the existence of a shared spatial regime in this historic area of Istanbul. This regulatory regime is characterised by co-ordinated processes of contamination and purification which connect Karaköy to the globalised streams of fear of disorder, decay, contamination, disease and, in particular, to the Modernist fear of chaos and terror.

Re:fuse, xurban's intended contribution to the Biennial, was conceived to include photographic research in brothels involving collaborations with sex workers, imitation crystal chandeliers, elements of ablution for purification and, 


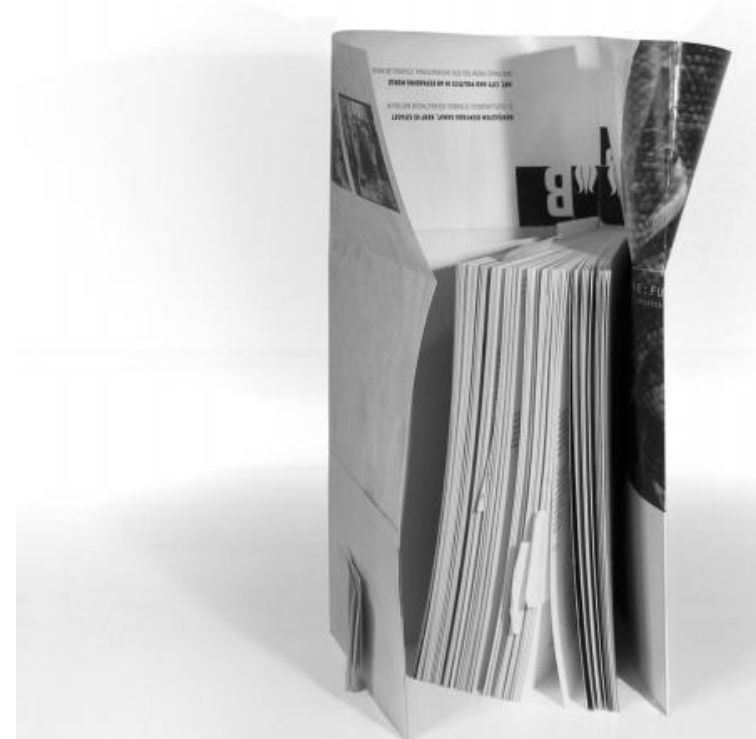

xurban, re:fuse, 2005, fold-out jacket of catalogue Art, City and Politics in an Expanding World accompanying the 9th Istanbul Biennial, photo: authors

most important, a transnational transfer of garbage collected from the Karaköy brothels to a Northern European museum. In repeated attempts, the proposed project was denied permission to photograph the 'official' brothels of Karaköy and the surrounding streets. Instead, the government's letters of rejection added weight to the issues of patriarchal affectation, rhetorics of contamination and rituals of cleansing brought up in advancing the original proposal. Obviously, the idea of shipping garbage from Turkish brothels to Eindhoven's Van Abbe Museum, which acted as a parallel exhibition space during the Biennial, had particular disadvantageous impact on some of the government's decisions on xurban's proposal. What became evident through the failure of carrying out the project is a circulation of anxieties which not only tap into the history of resentments towards Turkish populations but also touch upon deepseated Turkish worries of exposing Istanbul's consensual global appearance through contamination with the social realities of impurity, disorder and dirt. Inadvertently, the project had linked the ways in which official cultural policies take possession of the structures of biennials, art fairs and world congresses as expedient rituals of purification to the ways in which urban space is controlled locally. In keeping with this policy Istanbul has become a shrinking city in terms of its globally shared, managed and purified space and a rapidly growing 
city in terms of its zones of disregard. While being disavowed and repressed, the proliferation of these 'contaminous' spaces, black markets, shanty settlements, wastelands and improvised infrastructures, point at a much more general reluctance to address the failure of politically controlled and administered planning as one of modernity's key instruments. Having said that, it seems important to stress that this is not a particular point about İstanbul or any other city struggling to acquire a position within the space of flows in the new neoliberal world order. It is more a point about global policies of containment which seek to link zones of spatial contamination and contestation to particular territories, as if these territories and their populations would operate independently of the contradictory forces acted out upon them.

Rendering the enacted policies of containment legible, a significant number of geocultural art practices have recently focused on those whose lives are subject to the failed attempts to contain this global failure locally. Be it refugees, migrant labourers or detainees, the subject emerging from these works is a translocal actor bound to the spreading effects of informal economies. A paradigm related to the dynamics of this translocalisation and to its production of subjectivities is the so-called 'shuttle trade' (chelnochny biznes) or 'suitcase trade' (valiz ticareti) which has evolved from cross-border exchanges centred in the weakly regulated economic environment of the former Soviet Union in the 1990s and led to the rapid socio-economic transformation of the Istanbulite quarter of Laleli. What started out as casual business via tourist coaches crammed with plastic bags and simple suitcases quickly turned Laleli into a transnational hub of informal exports, mainly garments and leatherwear, in the range of US\$5-10 billion per year. Despite the enormous amount of goods shipped in suitcases between Turkey and the former Soviet countries, authorities used to classify these transnational activities as toll-free tourist purchases. As there seemed to be promising opportunities in Laleli, people from Azerbaijan, Moldavia, Romania and many other countries of the former Soviet Union moved to Istanbul and acted jointly to create a self-regulating urban space comprising little more than twenty blocks of houses encompassing all the essential infrastructure for large-scale transit trade. An unaccounted number of warehouses, showrooms, packaging services, hotels, restaurants and night clubs sprang up, all minutely aligned to cater to the traders' demands. In the wake of the collapse of the Soviet Union and helped by the relinquishment 
of cross-national controls, Laleli had been fully transformed from a residential neighbourhood to a bazaar of informal arrangements without paperwork or official inspection in less than a decade. ${ }^{4}$

Objects of Desire/A Suitcase Trade (100 Dollars Limit), a work by artist Gülsün Karamustafa shown at various western European venues between 1998 and 2001, bears on these trans-border economies which were critically encouraged by the authorities' connivance at the illicit trade. The main objects of her exhibitions consisted of suitcases filled with goods purchased on informal markets in Istanbul and brought across borders to be sold on to exhibition audiences. By locating the suitcase trade not within the particularities of a geographic context but through its proximity to the self-authorised structures of grey markets, informal trade, alternative economies and migratory ways of life amidst Western European contexts, Karamustafa confronts us with the seamless assimilation of informally traded goods into the regulated organisational structure of Western (art) markets. In so doing, her work not only emulates the existing spatial trajectories of informal network operations, but gives rise to an alternative engagement with the subjectivities constituted through these forces. It simultaneously inheres to reality, yet at the same time deploys an outside space which allows for an active redistribution of roles and activities outside the usual conceptual frameworks applied to discourses of informality, migration and globalisation.

There is a palpable current within recent documentary practices in the Turkish art world which focuses on the contradictory and conflictual conditions in which new and unforeseen agencies emerge and new alliances coalesce. We can trace such trajectories, for instance, in Can Altay's cartographic observations of the ways in which formal economies interlace with shadow economies as well as in Bülent Şangar's photographic examinations of the appropriation of functionalist urban space through traditional ritual practices or in Osman Bozkurt's documentations of people occupying interstitial spaces of the city in myriad ways. In 'We're Papermen' He said (2003) Can Altay outlines hidden and marginalised practices and relations of inhabitants by highlighting the methods and alternative cartographies employed by people who collect recyclable material from containers to make ends meet. What happens here operates apparently against the official system of waste collection and, in particular, 
against the official system of social organisation. In principle, though, it provides support to this system, as more material passes through its recycling industries. ${ }^{5}$ Documentary art practices like this often de-normalise usual investigations into such happenings, so as to reveal the instabilities in formal spatial organisation for modes of alternative engagement. Bülent Şangar, for instance, has produced a series of photographs Feast of Sacrifice (1997-99) of green spaces along motorways and main thoroughfares. The series portrays how during the feast of the sacrifice rural immigrant residents use these leftover areas to create a ceremonial space to sacrifice lambs, goats or other animals. In a similar way, Osman Bozkurt documents the appropriation of modern places of planning, carparks and green areas between Istanbul's motorways, - Carpark Highway Parks in Istanbul (2003) - for playing football, sunbathing, lounging, sleeping or having barbecues. The creative conversions and re-appropriations of urban infrastructures portrayed in these works delineate what we may call a contemporary 'art of practice', the everyday tactics employed by urban users to counteract the networks of social and spatial control. Establishing unusual trajectories of interaction between an imposed system and its users, these movements create spatial systems which contest the predominant politics of normalisation fostered by the 'suffocating alliance between neoliberal politics and Istanbul's Islamic middle class' ${ }^{6}$.

Inevitably, the image of the so-called Gecekondu plays a pivotal role in any such discussion. This term is generally used with reference to building structures that have been erected 'overnight'. Initially, small, single-storey shacks with a bit of land around were often set up spontaneously and collaboratively in close vicinity to industrial estates, offering modest and semirural accommodation for internal migrants. Notwithstanding the fact that these structures were lacking proper planning permission, their demolition could not be ordered by the local authorities even though deemed inhabitable. That more than half of Istanbul's housing had sprung up in this manner has caused farreaching conflicts within the bourgeois city and its understanding of spatial production. Istanbul's cosmopolitan citizens, the urban financial elite and some leading urbanists consider the Gecekondu to be a threatening and uninhabitable import from Anatolia, an unwanted parasite of agrarian origin obstructing forward-looking development. This attitude of disregard and denial positions the Gecekondu as contested space in the conflict between dominant 
high culture and the culture of the immigrants, while reflecting the tensions between globalisation and tradition within the city as a whole. ${ }^{7}$ Struggling against Gecekondu culture, efforts of socio-spatial integration on the part of planning authorities are still predominantly based upon the assumption that forcing order on top of what they perceive as urban chaos is for the general good. Interventions into urban space by the charismatic mayor Bedrettin Dalan, who came into office in 1984, have been described as excessively overstated; be it the construction of an all encompassing network of high-performance freeways including an expressway through the historic district of Tarlabaşı or the ongoing project of restoring the $22 \mathrm{~km}$ long Byzantine city walls. Over the last decades the precarious condition of the latter in the midst of decaying neighbourhoods had become a symbol for both the hoard of authentic Turkish values and the impoverishment of Istanbul.

\section{Accumulations}

Exacerbating this situation, a bustling site of high-contrast undertakings emerged in Istanbul's central district of Topkapi in 2005. The process of Istanbul's urban transformation saw the political gestures of reconstructing the Byzantine city walls and building the tracks of a state-of-the-art low-floor tram faced with kilometres of informal trafficking. This spontaneous black market took place just outside the gates of the historic city, along the construction sites of the high-capacity interchange between Topkap1 Edirnekap1 Caddesi and the eight-lane Londra Asfaltı. Squeezed in between newly delivered and derelict building materials, busy freeways and almost impassable heaps of crushed stone, tens of thousands of people formed an endlessly meandering and pulsating structure. The lower end of this formation is marked by the Metro station Ulubatlı, the upper end by Cevizlibağ, a new stop along the ultramodern tram line, which runs from Zeytinburnu past the Grand Bazaar (Kapal çarşı) to the old centre of the city and across Galata Bridge up to the Bosphorus. The merchandise, heaps of second-hand goods and clothes laid out on bare ground blending in with new TV sets, refrigerators, computers and pieces of furniture. In stark contrast to this 'wild' and bustling accumulation, the whole place is bordered with an immaculate but deserted layout of formal green whose ghostly abandonment is amplified by the garish colour of the artificially 
irrigated lawn. In 1852 Théophile Gautier wrote about this stretch along the city walls:

It is difficult to believe there is a living city behind these dead ramparts! I do not believe there exists anywhere on earth [a thing] more austere and melancholy than this road, which runs for more than three miles between ruins on the one hand and a cemetery on the other. ${ }^{8}$

The informal market invokes an archaic model of the city's organic emergence at the intersection of traffic routes and trading places. In the case of Topkap1, however, trade flourishes in the shadow of official urban planning, transforming the latter into a vehicle of informality. The widespread impact arising from this informal economy is not confined to the market's own dynamics. It is amplified by a series of secondary services linked to it: shuttle buses, street kitchens, intermediaries, suppliers, vendors and occasional street performances. It is through this bizarre entanglement of modern transport systems, symbolic sites of national renaissance and short-lived subsistence economies, through the complexities of legal work, third economies and informal trade, that this temporary market accounts for more than just an incidental set of happenings. Certainly, the mutual permeability of formal and informal structures, the aberrant utilisations of urban space and the acceleration of spontaneous cultural eruptions designate the emergence of new urban networks, trajectories and hierarchies.

In the summer of 2005, the informal market in Topkapi had grown to an agitated swarm-like shape more than two kilometres long. Thousands of people wandered around small piles on dusty sand, many of them barely distinguishable from dumped waste, vanishing among existing debris. The market generates a space in which a great variety of people spend endless hours looking, moving, aggregating, communicating, meeting other people. They constitute the sort of 'casual time' Michel de Certeau wrote about in his book The Practice of Everyday Life: 'Casual time appears only as the darkness that causes an "accident" and a lacuna in production. It is a lapse in the system, and its diabolic adversary.' ${ }^{9}$ This failure of or gap in functionalist planning, as Certeau has argued, cannot be excluded from the symbolic, ie, from the realm of rational calculation, without ignoring the actual discourse of the city. Put into 

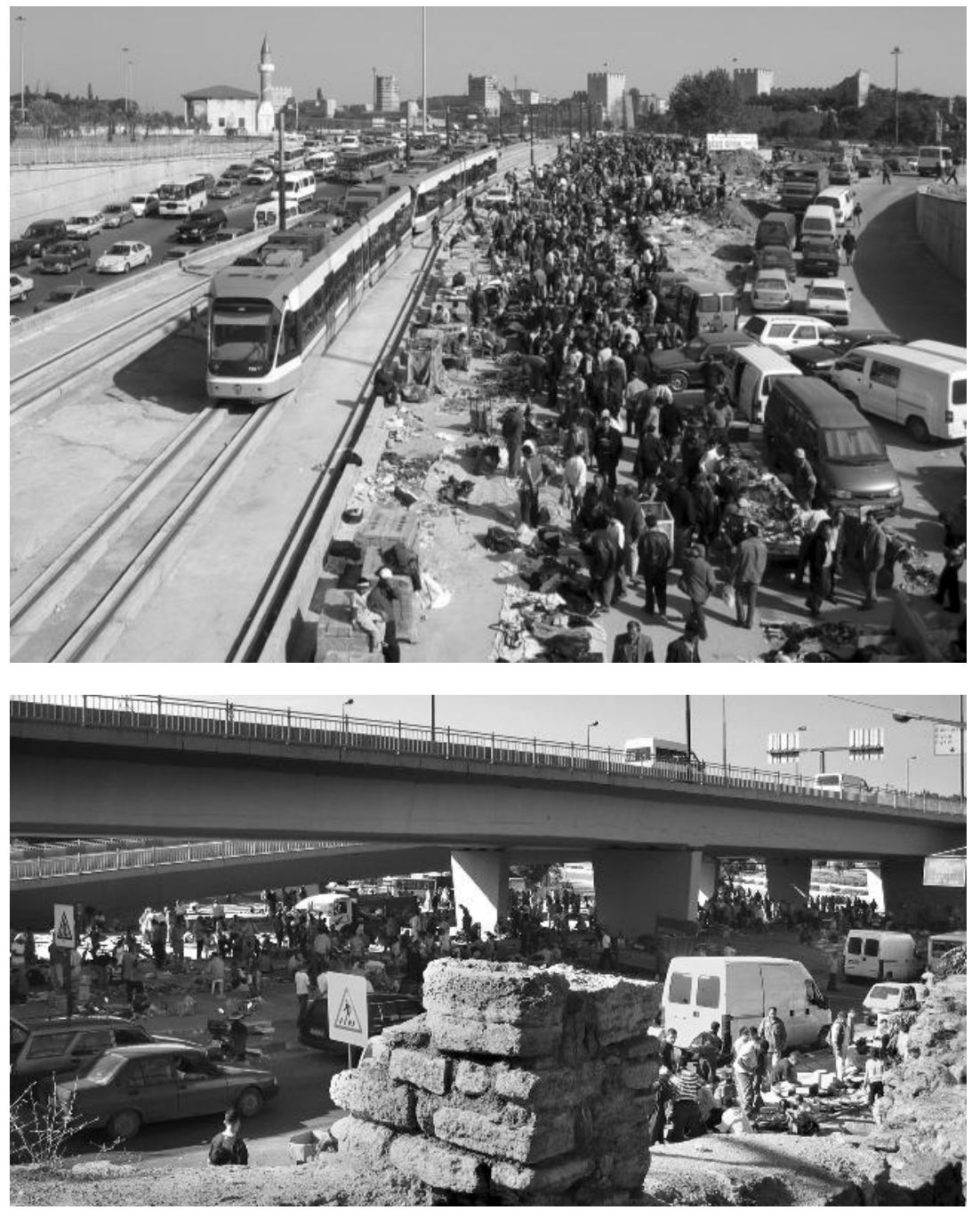

Informal markets outside the Byzantine city walls in Istanbul's district of Topkapi, 2005, photo: authors

shape along unforeseen occasions, the living practice of the city is an amphibian agent. It accrues from the indeterminacy of casual time while clinging tightly to the fictional character operating at the base of any kind of socio-spatial reality. It thus critically informs the tension between forces of fragmentation and globalisation through which the current de-aggregation and re-aggregation of the socio-spatial matrix is played out.

What black markets like Topkap1 render visible is the increasing pace with which wide-ranging networks of self-organised economies enter, inhabit and withdraw themselves from unsettled territories without being mitigated or isolated from the politics of formally organised space. There are neither 
recognisable borders nor consistent frameworks on whose grounds an exchange between systems would take place. These systems evolve on grounds not regulated through concise legal frameworks and so their status remains indeterminate up to a certain point. Flagging down a mini-bus at Topkapı market, we do not know if it will pull up, until we have actually boarded. We live, as Ernesto Laclau has argued, as bricoleurs in a world of incomplete systems whose rules we co-produce and revise by incessantly retracing them. After Laclau, it is precisely this struggle that allows for emancipation(s). In the middle of the unplanned performance we search for mythical and impossible origins without ever being able to overcome the impossibility of the task itself. What counts, however, is the struggle for decisions that are necessary for the very reason that there is no supervising and controlling total system. Contrary to the radical foundation of democratic society and controlling classification systems in the epic narratives of modernity, Laclau proposes a model of political practice that develops itself further along a plurality of acts of democratisation. ${ }^{10}$

At the same time it is important to consider that the apparently inexhaustible innovative energy of cultures faces an increasing susceptibility for acts of violence, particularly in the light of growing urban segregation. In this sense, the way we think about architecture as a political practice to instigate forms of cohabitation will more and more depend on the kind of relations we establish between space and conflict. The creative potential of conflict can be seen in its ability to hold back a blind totality. Such a totality usually aligns itself with two different poles: one is located by measures of neutralisation, the other one by unification. In the first case, the democratic public sphere is understood as a neutralised space of individual expression and in the second as a unified social entity. ${ }^{11}$ In both cases, conflict is seen as a force that undermines the emergence of productive spaces of democratic societies. However, if we depart from the premise that the platform put up for discussion, the emergent networks of informal place making, is not a plannable and definable formation but a contributor to an ongoing transfer of ideas and debates into the realm of spatiopolitical action, then conflict becomes the prerequisite for the emergence and growth of appropriate spaces of democratic coexistence. The immense potentiality of conflict thus lies in forging new modes of action which revise our mental imageries and among which violence is perhaps the most misleading one. 
As new conflicts emerge from the changing urban fabric, they direct our attention towards the new ways in which the presence of social and political exteriority has been constituted and expressed by the relation between urbanisation and historical forces. Considering, for instance, the political significance of the marketplace as city centre as it emerged in Western Europe in the twelfth century, Henri Lefebvre has reminded us of the historical fact that 'antiquity looked upon trade and tradespeople as external to the city, as outside its political system, and so relegated them to the outskirts' ${ }^{12}$ In constituting the outskirts today, informal activities are less bound to a specific territory in respect of the centre, but they are equally excluded from its political sphere. What is in current terms called 'peripheries', though, is a highly mobile situation which creates its own leakage paths into the disintegration of the old binary system of centre and periphery. If uncertainty is the place of network transformation, then the shared endeavour of the practices supporting this disintegration is less to do with framing resistance through territorial claims than with reclaiming transformation itself as a place of resistance. One characteristic that emerges through this disintegration is that in a weakened institutional environment such global microstructures generate sites of counterglobalisation based on a de-territorialisation of cultures. Many of the newly emerging informal markets, for instance, are hubs of migratory routes whose idiosyncratic complexity reflects the tension between traditional economies, black markets and the new conditions of deregulated and liberalised capital markets. The dynamics of these sites highlight the network character of the radicalised and deregulated flows of people, capital and goods worldwide. One of the effects this network phenomenon creates is an increased transnationalisation and hybridisation of cultural claims and expressions: a sprawl of a myriad of parallel worlds existing next to each other, while producing new and experimental modes of mutuality and collaboration.

\section{Overflows}

Drawing on analyses by the Swiss sociologists Urs Bruegger and Karin Knorr Cetina, Brian Holmes has recently pointed out how markets can be described as knowledge constructs. In his account they act as epistemic objects within a 
sphere of technological and institutional frames. They are highly unstable and variable in their nature as they always remain incomplete and changing. Their variability makes them seem alive and unpredictable. ${ }^{13}$ Informality adds another epistemic dimension to markets. As much as they can be conceptualised as knowledge construct, they also act as knowledge filters, allowing only parts of the goings-on of the market to become intelligible, while secrecies, dubious relations and risky transactions are to remain undetected. And it is particularly this part of knowledge production, the deferral, obfuscation and active withdrawal of knowledge that accounts for much of the activities that define informal trade, in addition to accounting for the spatial emergence, dispersal and re-aggregation of informal markets. They remind us that culture is not a zero sum game in which complementary regimes add up to some notion of totality. What becomes evident through these characteristics of informal markets is not only that official and informal market systems, planning and informal growth, are bound to each other in a non-complementary way, but also that the informal offers another model of how different worlds touch upon each other, how different systems congregate and how they interact. There is a double edge to this new networked situation. On one level it tends to signify the end of our control of the territorial map, of the idea that the world is composed of objects and not of relationships, processes and dynamics, while on another level these very relationships are regulated through technological and political means that do little more than consolidate the control society. It seems consistent with the growing strata of geographies and counter-geographies, technologies and counter-technologies, that more and more transversally structured art and architectural practices get involved in the production of connective relationships, be it through interventionist or cartographic work. However, the question remains, as Brian Holmes has argued, how to use the tools and representations generated by this multidisciplinary research ${ }^{14}$ - how to use the network installations of Gülsün Karamustafa, how to use the cartographies and pictorial diagrams produced by artists like Can Altay or Osman Bozkurt, and how to use the operational model of a networked research group like xurban. How can we trace the ruptures, inconsistencies and fragmentations presented and negotiated through their work? As we have established before, contemporary network practices do not evolve in isolation from dominant culture, rather they manage to create alternative expressions from within, allowing art and architecture to become co- 
producers of counter-geographies. Given this complex entanglement in global systems, how can we conceive of the ways in which asymmetries arise within the global streams of institutional complexity?

Processes of framing are never fully complete when it comes to informal structures, because their framings are always tentative, in expectation of detection and therefore always on the run, hiding from being brought into bright daylight and therefore allowing for an undercoding of informal structures - this means, among other things, that the relatedness of informal markets is based on moving things along rather than on bringing them into the right place once and forever. At the same time we are confronted with an overcoding of such structures through their amphibian character: they occur on more than one site, they are multi-locational, happening in between places or occupying interstitial spaces of the urban fabric. Equally, the political subject extracting itself from the dominant matrix of classification on these terms is both incomplete/fragmented and amphibian. It is the coming together of both aspects that accounts for the ways in which conditions of indeterminacy are incorporated into the processes of subjectivisation.

With respect to formal or informal networks, there are always relations which defy framing through overflowing the initial frame. In an 'ideal' situation, framing dissociates individual agents from one another and allows for the definition of objects, spaces and goods which are perfectly identifiable. As one withdraws from old relations, transformation takes place through turning associated goods into commodities. ${ }^{15}$ The transformation that pertains to informal structures, has much more to do with a mode of prolonged entanglement. It is not despite but because of this entanglement that such structures transform themselves into something new. They reshape themselves into amphibian structures - they multiply instead of disentangling themselves, producing a volatile body of knowledge which passes between informal global structures and the subject emerging from them. In social or political terms, new subjectivities emerging from the current flows of migration, deportation and resettlement become a nexus of contacts between conflicting worlds. They remain entangled while reworking their entanglement inside themselves, creating the subject as a fragmented battleground, as a potent and contested mobile site. 
There is a strain within contemporary psychoanalytic models of intersubjectivity which cautions against the condemnation of conflicts and disruptions within spheres of relatedness. Accounting for an imperfect but perfectly suitable model of development, they argue for a climate of sustained contradictions within such spheres. In drawing attention to such models, we want to turn to the work of Jessica Benjamin, an American psychoanalyst focusing on relational theories of the self, and bring her approach together with relational aspects of the multitude outlined by Paolo Virno in his A Grammar of the Multitude. ${ }^{16}$

Benjamin argues for the experience of a space that allows both experimentation with possible worlds and acknowledgement of existing outside structures. ${ }^{17}$ This is an argument against the prevalent ideology of clear breaks between the intrapsychic and intersubjective, the inner world of fantasy and the outside world of reality, ie, the ideology of breaks between two competing systems and the way discontinuation is construed. In compliance with Virno's grammar of multitude, her model foregrounds a shared practice in the sustaining of contradiction, in the simultaneity of both worlds. For Benjamin, the tension of sustaining contradiction over an extended period of time may break down, and one system may start subordinating the other, but what counts in her view is the ability to restore and repair the relationship. The main point about Benjamin's resistance against the idea of clear breaks or sequences and her preference of sustained contradictions is that relatedness is not a model characterised by continuous harmony, but one characterised by continuous disruption and repair. In this model there is no normative ideal of balance that equates rupture with failure and fantasy with pathology. She concludes that rather than seeking perfection in a complete move towards the realisation of one particular form of organisation, namely the one perpetuated by hegemonic culture, while totally abandoning all other forms, we should opt for a space in which the messy and contradictory side of creativity acts out its generative forces and, in so doing, reworks the conditions on which it grows. ${ }^{18}$

There are two aspects in Virno's grammar of multitude which echo Benjamin's argument. One is the way in which Virno describes the subject as a battlefield of different forces. Individuation, he argues, is always incomplete and 
fragmentary. ${ }^{19}$ There is always a residue of pre-individuality which does not fully translate into singularity. Following Virno's reasoning, the subject is both pre-individual and individual, both anonymous general intellect and nonreplaceable singular being. He implies that in the age of the multitude, the subject in all its dimensions is a site of conflict decidedly marked by the question of whose particular interests are allowed to enter the individuation process. The other aspect is the way in which the multitude interacts with dominant models of social and political organisation and how it unfolds its particular strengths. Rather than operating through the dynamics of polarisation and transition from one point to another, eg, from the concept of the people to the concept of the multitude, Virno understands the network agency of the multitude as a reworking and redefinition of many of the notions which were characteristic of an earlier economic and political period. New modes of social expression and social interaction are invented within dominant culture. Virno concludes that the appropriation and reshaping of the networked society by the multitude adheres to a form of substitution which capitalises less on the principle of discontinuation and much more on practices of sustained contradiction. This is a substitute which does not replace outside reality. It neither supersedes nor emulates it through the invention of a surrogate. It simply operates from within. This form of substitution is neither parasitic nor abysmal. It is a structural mode conditioned by the same forces that have brought it about in the first place, and therefore it shares the same operational logic.

In other words, in what we conceive as a network, there is a topological tension between the organisational pattern and the ideas and meanings developed by its actors. The role of this tension is to sustain the incessant transformation of the network, to defy a total topological stability which would turn a network into a fixed identitarian structure. Thus, in a political sense, network agency is based on a notion of deformation - networks form topological possibilities out of which new protagonists emerge as network effects. There is an essential asymmetry in place between the present state of networks as representational instruments and their actors; an elementary moment of non-recognition pertaining to the relation between the present structure and the structure to come. This asymmetry does not only facilitate a reworking of the individual within a new relational ethic through interventions into the social imaginary. It 
also fashions and refashions the unstable place of network creativity through an incessant and irreducible transformation of ends that are never given.

1 Jason Burke, 'The forgotten migrants who still wait to reach the promised land', The Observer, 24 December 2006, p 25

2 Maurizio Lazzarato, 'To See and Be Seen: A Micropolitics of the Image', in Anselm Franke, ed, B-Zone - Becoming Europe and Beyond, Actar, Barcelona, 2005, p 296

3 Michael Hardt and Antonio Negri, Multitude, Hamish Hamilton, London, 2005, p 83

4 Çağlar Keyder, ed, 'A Tale of Two Neighborhoods', Istanbul: Between the Global and the Local, Rowman \& Littlefield, Lanham et al, 1999, pp 177-179. See also Deniz Yukseker, 'Trust and Gender in a Transnational Market: The Public Culture of Laleli, Istanbul', Public Culture, vol 16, no 1, winter 2004, pp 47-65.

5 Bartolomeo Pietromarchi, The [Un]Common Place - Art, Public Space and Urban Aesthetics in Europe, Actar, Barcelona, 2005, pp 178-179

6 Vasıf Kortun and Erden Kosova, Szene Türkei - Abseits, aber Tor!, Verlag der Buchhandlung Walther König, Köln, 2004, p 60

7 Hande Birkalan, 'Telling the Story Differently: Experience of Gecekondu', annex, 2, September 2003, p 3

8 Orhan Pamuk, Istanbul - Memories and the City, Alfred A Knopf, New York, 2005, pp 231-232

9 Michel de Certeau, The Practice of Everyday Life, University of California Press, Berkeley and Los Angeles, 1988, p 202

10 Ernesto Laclau, Emancipation(s), Verso, London and New York, 1996, pp 79_ 82

11 Ernesto Laclau and Chantal Mouffe, Hegemony and Socialist Strategy: Towards a Radical Democratic Politics (Second Edition), Verso, London and New York, 2001

12 Henri Lefebvre, The Production of Space, Blackwell, Oxford, 1991, p 265

13 Brian Holmes, 'The Artistic Device - Or, the articulation of collective speech', online: http://ut.yt.t0.or.at/site/index.html (accessed 31 December 2006), 2006 
14 Brian Holmes, 'Cartography of Excess: Bureau d'Etudes \& Multiplicity', online: http://ut.yt.t0.or.at/site/index.html (accessed 31 December 2006), 2002 15 Michel Callon, 'ANT - The Market test', in John Law and John Hassard, eds, Actor Network Theory and after, Blackwell, Oxford, 1999, pp 191-195

16 Paolo Virno, A Grammar of the Multitude, Semiotext(e), New York, 2004

17Jessica Benjamin, 'Recognition and Destruction: An Outline of Intersubjectivity', Like Subjects, Love Objects: Essays on Recognition and Sexual Difference, Yale University Press, New Haven/CT, 1995

18 Ibid

19 Virno, op cit, p 80 